\title{
Education and Health: Epidemiological Indicators Can Improve the Continuing Education Process
}

\author{
Érico Faustini' ${ }^{1}$, Claus D. Stobäus ${ }^{2}$, Juan J. M. Mosquera ${ }^{3}$ \\ ${ }^{1}$ Postgraduate Program in Medicine, Pontifical Chatolic University of Rio Grande do Sul, Porto Alegre, Brazil \\ ${ }^{2}$ Postgraduate Programs in Education and in Biomedical Gerontology, Pontifical Chatolic University of Rio \\ Grande do Sul, Porto Alegre, Brazil \\ ${ }^{3}$ Postgraduate Program in Education, Pontifical Chatolic University of Rio Grande do Sul, Porto Alegre, Brazil \\ Email: stobaus@pucrs.br
}

Received 5 September 2014; revised 3 October 2014; accepted 21 October 2014

Copyright (C) 2014 by authors and Scientific Research Publishing Inc.

This work is licensed under the Creative Commons Attribution International License (CC BY).

http://creativecommons.org/licenses/by/4.0/

(c) $($ i) 0 pen Access

\section{Abstract}

In the field of Health Education, understanding human development is essential, taking into account a set of actions that can promote the protection and care to a better child development, so we researched about the evolution in epidemiological indicators related to child development, through literature review and systematic data collected on public system, in Rio Grande do Sul, a state in south Brazil. For this, we do a review that brought together elements of updated on epidemiological and social indicators: changes in the understanding of the processes health and disease, various public health policies that influence personal and social behaviors, especially for parents and caregivers of children. The findings allow seeing that data about child with low birth weight are inversely proportional to the number of years of parents study, mainly from 8 years of schooling; that actions of Health Education can be aimed at doctors, caregivers and pregnant; and that reference systems ensure correct referrals. As ultimate implications, we suggest public policies that enable reduce neonatal mortality by investing in access more the formal Education, encouraging at least the completion of elementary education. We can also encourage medical continuing processes that can observe continually the data that are contained in several public data systems.

\section{Keywords}

Health Education, Continuing Medical Education, Teacher's Education, Public Health, Education 


\section{Introduction}

The infant mortality rate is an excellent indicator for the assessment of quality of life and efficiency of the health system implementation.

The state of Rio Grande do Sul, in the extreme South of Brazil, collected annually epidemiological data, for example about child and adult morbimortality, birth, primary attention indexes, so we can use it for analyzing the evolution of epidemiological indicators and propose some interventions. Our idea was the research about the evolution in these epidemiological indicators related to child development, and complementing with the authors we read.

As we saw observing these data, there were significant results as the reduction in child mortality, in recent decades among Brazilian federal states. Historically, since the 1970s, the infant mortality rate (IMR) showed a steady decline. After 1997, data obtained from the Health Information Center at the State Health Secretariat of Rio Grande do Sul (Rio Grande do Sul, 2005), indicaterd that IMR in Rio Grande do Sul reached 15.9, and that in the next seven years there were no reduction of this indicator, even in this period varying between 15.1 and 15.9 (with the exception of 1998, which showed an IMR of 17.2).

This motivated an act of technical Section of Child Health and Adolescent Health Department shared the Secretariat of Rio Grande do Sul Health, with political support from the state through the Live Program for Children, with the main cities of the State during the years 2005 and 2006, in order to give the opportunity to discuss about local causes and reasons that led to stagnation in infant mortality.

This action did not intend to take ready solutions to these municipalities, but to build with them a continuing educational vision, to a reconstruction management focused on maternal and child health from a reading/rereading of the local reality.

\section{Literature Review}

According to a study of Duarte (1992: p. 425), "the different components of infant mortality can react different to the availability of social infrastructure and medical-sanitary interventions".

Goulart et al. (2003: p. 303) showed that the infant mortality surveillance, by identifying, capturing and monitoring of children at risk, pointed to a favorable evaluation of this type of program.

To study about the data obtained from the municipalities, it is necessary form a group of from some of these realities, as Mosquera \& Stobäus (1984: p. 13) say, "to be able to structure any line of action, it is necessary, first, to have as a reality that assume the basic knowledge to be able to focus on it through a dynamic knowledge and action".

For this action at the local level, we rely on a prior resolution of the State (Rio Grande do Sul, 2003a) about the need to create a network of child protection risk. Municipalities started to identify, from birth, children with these risk factors. The same from maternity discharge were scheduled for consultation in the Health Units.

Considering the pact for reducing child mortality and the need to reduce child mortality, the Ministry of Health established the National Committee for Prevention of Child and Neonatal Death (Brazil, 2004), adapted to each State.

Research of Formigli et al. (1996: p. 40) showed that the main problems related to infant deaths were rooted in poor organization of health services.

As Mansano et al. (2004: p. 331) observed, describing the experience of another South State, Paraná-BR, the research on infant deaths provides interventions that promote these reduction.

The action research on infant deaths was started in Rio Grande do Sul in the year 2001, however, the percentage of investigations in the early years ranged between 6\% and 15\%. In 2005 and 2006, as a way to better understanding of the event infant death, the State invested more into this strategy. This action was based on a resolution of the State which regulates research on infant deaths (Rio Grande do Sul, 2003b), carried out by municipalities within 45 days after the occurrence of the event was made by the mother in the hospital and when the death occurred there, following a different preset for neonatal and infant died later.

Investigation of death from prematurity showed a relationship with age (adolescence mothers), not (very high) maternal education, and (few) number of prenatal consultations. To Drumond, Machado \& France (2007: p. 162 ), there is underestimation of the underlying cause of death on the subject of maternal conditions by preventing adequate care during labor. 


\section{Methodology}

Of the total of 496 municipalities in Rio Grande do Sul-BR, classified by the occurrence of the average number of deaths in children under one year of age in the last five years, we was found that $75 \%$ of infant deaths were concentrated in 51 of these municipalities.

These 51 counties were the largest population and economic representation of the State and have received throughout the years 2005 and 2006, with regular intervals, combined between the technical state and the city, a visit from a technician from the State Department of Health. In this period, 419 meetings were held with these municipalities, with an average of one visit every 13 weeks.

In the first visits we gathered all municipal leaders involved with children's health, such as: Mayor, Municipal Secretary of Health, responsible for the actions of the Child and Woman of the Municipal Secretariat of Health, Municipal Department of Education, Office of the Attorney Childhood and Youth Ministry of Child Health, Lyons Club, Rotary Club, the representative(s) Hospital site(s) and Family Health Program.

With this large group we made an open discussion about why locally infant mortality was difficult to reduce, and sought to relate the reason for the permanence of the level of IMR at the local level, without tendency, relating it to factors associated, with the local reality of every county.

How common features, these municipalities had a higher concentration of deaths in the early neonatal period (up to six days), without, however, being the late infantile mortality (from 28 to 365 days) a solved problem. With that, we encouraged the discussion about what could be done to reduce the deaths of the latter period.

We observed that the deaths occurred in late childhood, in these municipalities, and mostly had some characteristics in common, such as low birth weight, low maternal education (illiterate or have less than three years of study), or multiparous teenage mothers with three or more children and/or history of previous deaths of children, or malformations.

These findings confirmed previous Menezes et al. (1996, 1998), César et al. (1997) and Passebon et al. (2006) researches, about the risk of illness and death in the first year of life.

Thus, we agree with the State and County, to work initially with the creation of a network of protection of children with these characteristics.

This consultation did not occur if the due date was cause for home visits by the health team. After this $1 \mathrm{st}$ consultation we guarantee intervals of approximately 30 days, marking the next and so on during the 1 st year of life, encouraging to home visit of all these children and, in particular, of defaulting. These service involved multi-professional health team, in an interdisciplinary approach, and could vary by each municipality.

In the constitution of the groups, generally we had the interactive participation of physician, nurse, dietitian, social worker, psychologist and health agent. Another consensual action from the meetings and encouraged by the staff of the state was the investigation of data about infant death, as the rates are part of the Primary Care Indicators agreed by municipalities seeking qualification of municipal management (Brazil, 2001).

This script was standardized by State and previously discussed with the Regional Health and municipalities, perfecting models used in previous years. The information was recorded later in a computerized program, specifically created for this purpose, and sent electronically to the Health Section of Child and Adolescent State Department of Health.

Fruit of the predominant neonatal mortality, especially in the first six days of life, a relevant discussion carried out in municipalities with our presence, with the question: Why this happened?

First we discuss about possible reasons for these deaths, and it was noted as the primary cause related to prematurity, then cases of malformations and perinatal anoxia. However, these causes by itself did not include the complexity of the event death.

We chose at first in how city do prenatal visits. Issues related to the capture of pregnant, the number of queries, the realization of basic tests during prenatal, tetanus vaccine and a puerperal interviews were discussed.

There was a difficulty in obtaining these data from the local level. The Program for Humanization of Prenatal and Birth (named in Portuguese PHPN), developed by the Ministry of Health, is an important tool that has helped the local level for the implementation of their actions (Brazil, 2000). We say again that it is a difficulty of obtaining data from prenatal SISPRENATAL Program, and this encourage the use of a computerized information system and monitoring PHPN. This system allows the monitoring of the above data, facilitating the actions at the local level. 


\section{Results}

In 2004 and 2005 a decrease of IMR in the state of Rio Grande do Sul, which was not seen for almost a decade, reaching these years, rates of 13.6 and 13.1, respectively (Figure 1).

The reduction was due to the fall of IMR in the two components of infant mortality: late neonatal and infant. In 2005 and 2006, respectively, neonatal infant mortality rate was 9.1 and 8.8 and the late childhood was 4.5 and 4.3 (Figure 2 and Figure 3).

The identification of children at risk in the state of Rio Grande do Sul during 2006 revealed 34.41\% of children in this situation (Figure 4).

Data on infant deaths have reached percentages above $90 \%$ in recent years in the state of Rio Grande do Sul (Figure 5).

Regarding pregnant women, considering the users of the Unified Health System in Brazil (named in Portuguese SUS), an increase in uptake of the same for conducting pre-natal, reaching percentages above $70 \%$ in the years 2005 and 2006, and more 50\% of the pregnant women were taken up to 120 days of gestation (Figure 6).

The conclusion of prenatal capture, considering up to 120 days of gestation, conducting at least six consultations during pregnancy, with the realization of all basic tests recommended by PHPN, anti-tetanus vaccination and a puerperal interviews reached more than 20\% in the years 2005 and 2006 percentages, suggesting along with important fundraising opportunity for growth in the state (Figure 7).

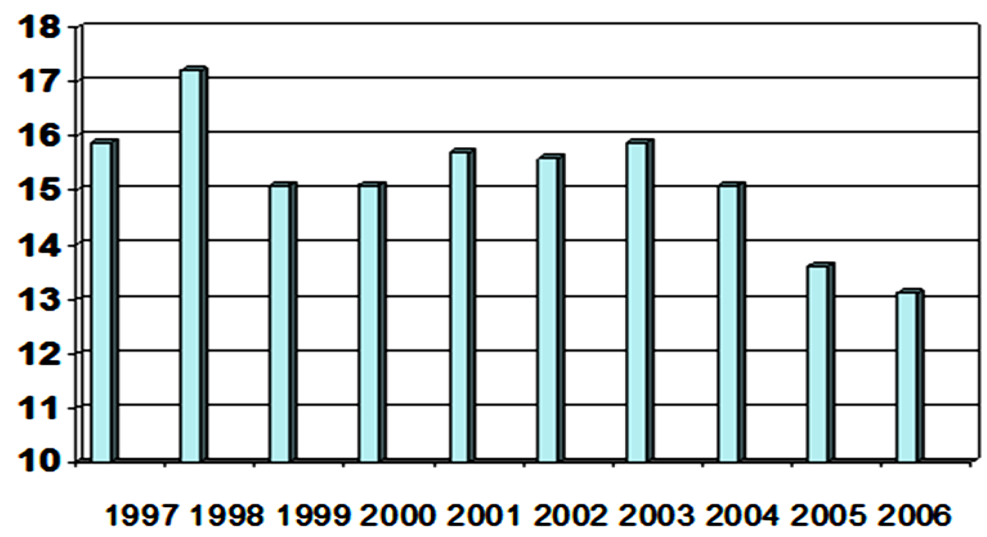

Figure 1. Evolution of the rate of infant mortality in Rio Grande do Sul, 1997-2006. Source: Center for Health Information, State Secretariat of Rio Grande do Sul.

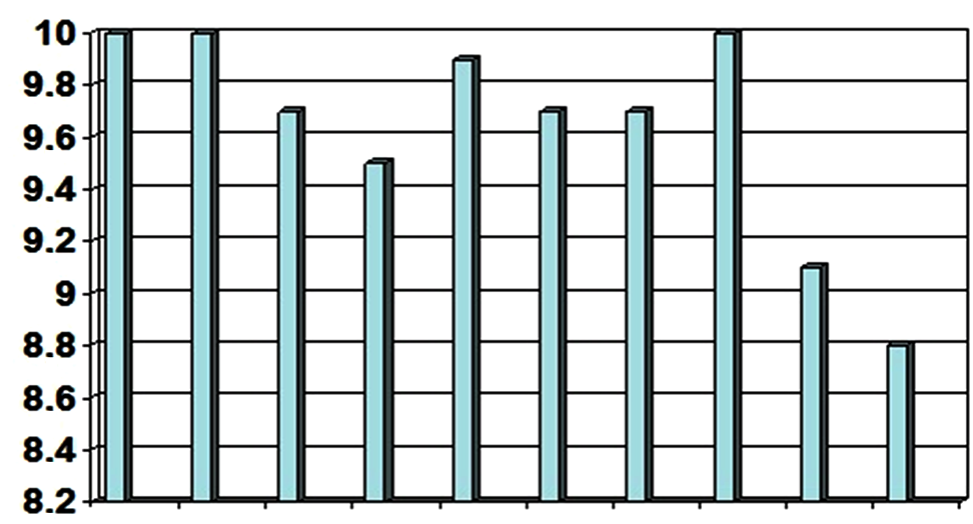

1997199819992000200120022003200420052006

Figure 2. Rise of the neonatal infant mortality rate in Rio Grande do Sul, 1997-2006. Source: Center for Health Information, State Secretariat of Rio Grande do Sul. 


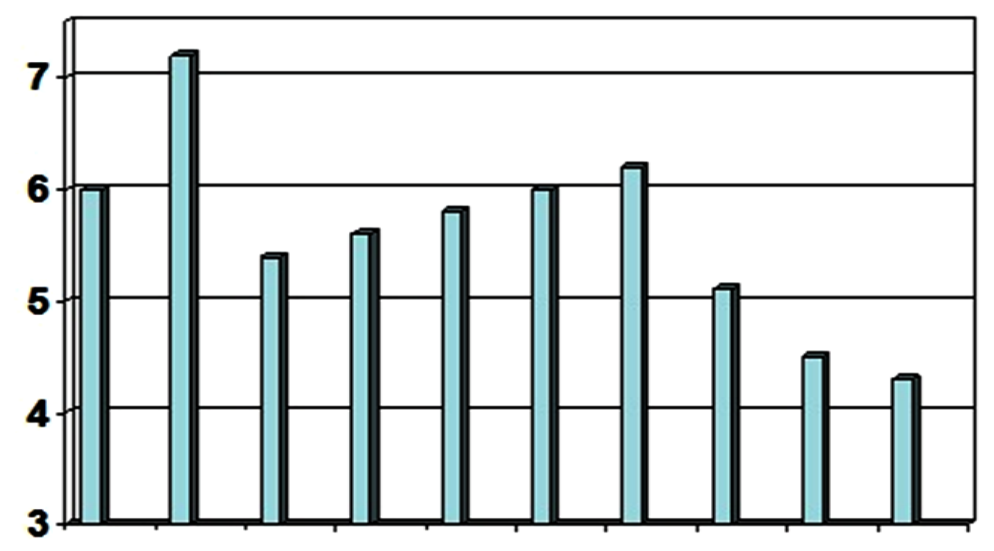

1997199819992000200120022003200420052006

Figure 3. Evolution of late infant mortality rate in Rio Grande do Sul, 19972006. Source: Center for Health Information, State Secretariat of Rio Grande do Sul.

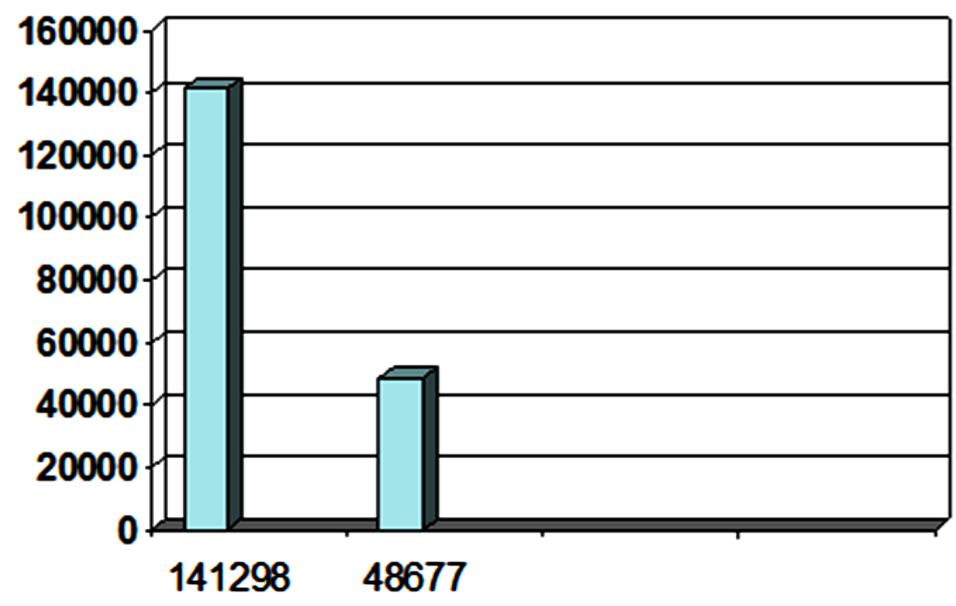

Figure 4. Identification of children at risk in the State of Rio Grande do Sul, 2006. Source: Health Section of Child and Adolescent, State Secretariat of Rio Grande do Sul.

\section{Discussion}

The actions we propose and done over the years 2005 and 2006, in a educational basis, in collaborative interaction between us, State and local manager, allow us a number of qualitative considerations, which we will do next, and we believe that can be based under theoretical and also practical point of view, the why the results obtained, especially the reduction of infant mortality hitherto stagnant for almost a decade.

The development of action to protect children at risk led to a greater integration of the healthcare team and increased knowledge of family socio-cultural reality of these children, allowing actions planned from this familiar knowledge interventions.

According Gomes \& Pereira (2005: p. 362-363), "it is necessary that public policies come in family support in situations of social vulnerability not only in relation to income, but also in relation to access to goods and social services". Working with the child under risk approach, who is a multidisciplinary and interdisciplinary approach, meant to increase understanding of health and disease processes to which it is subject, recognizing often the vulnerability and fragility of their family environment because of the risk.

The investigation of child death has the merit to overcome the simple classification of causes of death ob- 


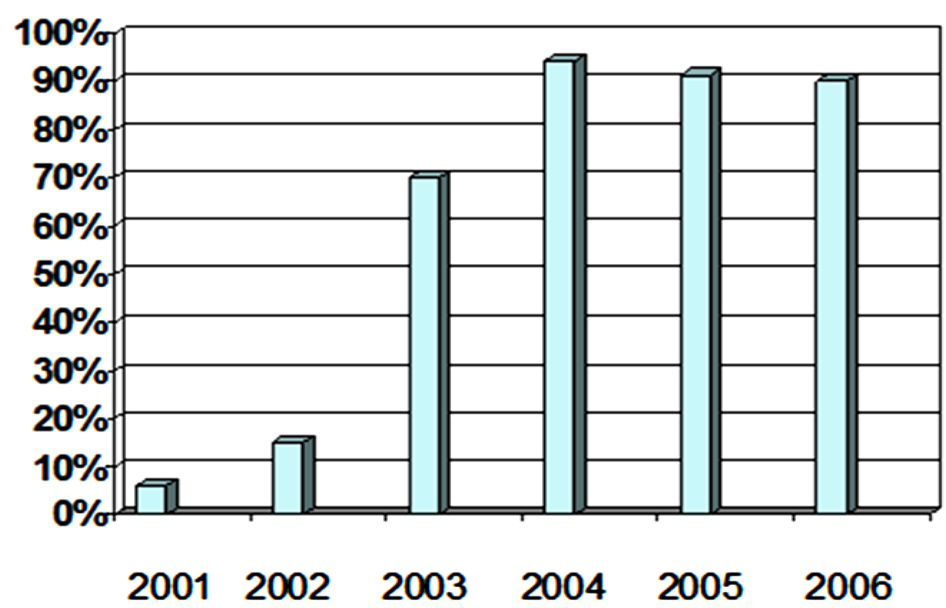

Figure 5. Percent of child deaths investigated in the State of Rio Grande do Sul, 2001-2006. Source: Health Section of Child and Adolescent, State Secretariat of Rio Grande do Sul.

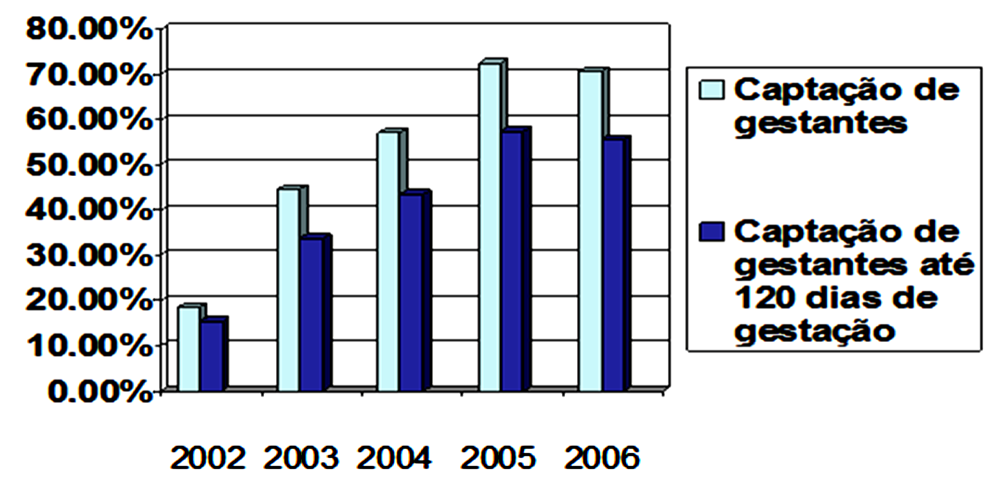

Figure 6. Percent uptake of pregnant users of the Health Care System for the realization of prenatal care in the State Rio Grande do Sul, 2002-2006. Source: DATASUS, Report indicators SISPRENATAL.

tained from records of death certificates. The hidden face of death can be revealed, showing its many implications and the complexity of this event, favoring a better local knowledge and making new decisions.

In this sense, we agree with Goulart, Somarriba \& Xavier (2005: p. 722) "detailed investigation of infant death in order to understand it beyond its numerical significance and documentary, appears to be important as a subsidy for the proper planning of interventions".

These two actions deepened the information SINASC System (Births) and SIM (System Mortality) allowing a wider knowledge of the threats of illness and death in the 1st year of life. The richest of all actions was undoubtedly upon accession to PHPN, fostered by the adoption of SISPRENATAL system.

The adoption and discussion of SISPRENATAL system provided a rich debate about health programs and the population adherence to them. From monitoring the uptake of pregnant women, subsequent consultations, their exams, tetanus shot and puerperal interviews, we can reassess the system of local health as: efficiency and effectiveness, importance of effective communication to achieve goals, intersectional role in the health and participation of the target population as agents of their own health.

According to the data of study of Silveira et al. (2001: p. 138), the monitoring of pregnant women by the public had a "low adherence to professional records and, probably, to perform the recommended procedures of consultation, as well as poor adherence of mothers to prenatal program". Our experience has shown that the success of a Health Program depends not only on its "installation".

According to Carvalho (2004: p. 677), "for the Brazilian reality incorporating assumptions and strategies for 


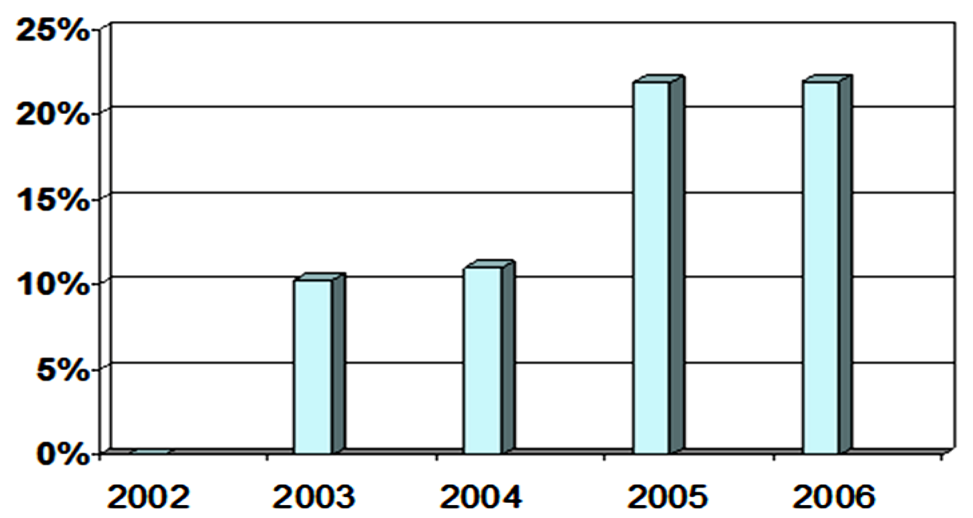

Figure 7. Percentage of pregnant women in the state of Rio Grande Do Sul, users of the unified health system, which concluded the pre-natal as PHPN, 2002-2006. Source: DATASUS, Report indicators SISPRENATAL.

health promotion in SUS should provide answers to the challenges of ensuring access to quality goods and services and the production of autonomous individuals and socially responsible".

In our experience we have seen the importance of all subjects perform with autonomy, and the role of active agent in this process, with the appropriation of the same by the subjects involved with the health issue, from rereading and reconstruction adapting it to the characteristics and needs of the local level are critical to your success, and stimulates the creativity of each subject, providing opportunities for new ways of doing.

For Stobäus \& Mosquera (2004: p. 157), creativity is not conformity: "it involves original, new and different points of view and ideas openings. Means seeing with several different ways something which seems to have on$l y$ one interpretation. The line indicates reproducibility, repeat".

There should be a special motivation, passing by local managers, healthcare and servers population to be assisted. We had a major qualitative breakthrough in the understanding of health and disease and health management process. Everyone could discuss and review their health systems and see the importance of public involvement in the process to your success.

The early identification of a pregnant woman for your monitoring has two main variables: the possibility of easy access to the health system, and the membership of the pregnant health action. The first is dependent on the local manager, but the second depends on a process of appropriation by these women of the importance of taking care of your health and the health system response to the expectation of receiving a quality service. Here we can see the importance of caregivers and also graduate students, i.e. in their residence, stages, seminars, regular or extension courses.

Spontaneous demand for the service of the pregnant woman is linked to the development of their autonomy with an appreciation of their self-image and self-esteem and the importance of caring for your health. Move with various taboos and concepts, such as, pregnancy poses no risk, I have had other pregnancies without problems.

The search process facilitated the access and delivery of quality of care provided various questions, such as:

Employees are becoming more committed?

- Are all the health systems committed, what are your questions?

- What are the anxieties generated by changes? How to treat the same?

- The Health System is corresponding to what is expected of it?

- When everything seems okay, because the funding does not rise? How are the people watching and participating in this process?

- What do the population adhere (or not) to the management process?

- How is the participation (or not) of the population? There are groups, like teenagers, who deserve special attention. How to reach them?

- How to involve formal education to perform in line with health and working these issues with students?

The reflections motivated by these questions above contributed to the improvement of management at the local level. We can made also links to the graduation courses at Health area, how do they develop this interconnections, in the inter and multidisciplinary way?

The main consequence of the actions developed in meetings with various municipalities, by its character of 
Health Education give us the questions in a theoretical order, attempting to provide answers to a bigger "experience": how do we define what is Education Management in Public Health?

From our lived experience we can define it as an intentional action that aims to change management practice within the Public Health from based on reading only official data in direction to rereading also the local reality reflection and necessities.

This (group) decision and definition leads us to a search of the characteristics of an Education for Management in Public Health. But, what are the characteristics that have this intentional action that seeks to change practices from reading (and rereading) the local reality?

Based on our experience, we list the main features of these actions as suggestions to "think and move":

a) The process benefits from the participation of a foreign subject to the local environment (socio-cultural animator).

b) The subject of local realities needs to be motivated to action.

c) A single and complete model to be applied does not exist.

d) The pace of the educational (learning and teaching) processes in the management of health problems, even in such situations, is not uniform.

e) The results can be advances and setbacks, due to the diversity of causes involved in Public Health.

As intentional action, it tends to produce effects. Thus, in our experience, we found the following effects of the process for Management Education in Public Health:

a) Better (critical) knowledge of the health and disease processes, from general to local levels.

b) Making decisions based also on local reality.

c) Questioning critically the practice itself.

d) Participation and consequent commitment of all subjects in the decision making processes.

e) Inclusion of the "users" (citizens) of the Health System as active subjects in their health process, facilitating the development of their autonomy.

f) Reflections in how to introduce and maintain continuing education in Health area courses of graduation and post-graduation.

\section{Conclusion}

The experience about the use of these (short) two years data showed the importance of an educational process for the approximation of the healthcare practices' attention to the management of this assistance, respecting local realities. In the process of Health Education, where it seeks to strengthen the autonomy and the participation of subjects, we think we showed the importance of an action directed to the Continuing Education (management) as a mechanism to enhance the results in the area of maternal and child health.

As we can see, the most important findings are that data about children with low birth weight are inversely proportional to the number of years of parents study, mainly from 8 years of schooling; that actions of Health Education can be aimed at doctors, caregivers and pregnant; and that reference systems ensure correct referrals that can be used for discussion end improve of interventions.

Also we suggest a reflection about the idea of putting into the graduation, post-graduation curricula and extension courses and the idea of manipulating the continuous data obtained at the official public data systems, so we can also encourage in direction of a Medical Continuing Education.

\section{References}

Brazil (2000). Programa de Humanização no Pré-Natal e Nascimento (PHPN) (Program for Humanization of Prenatal and Birth). Brasilia: Ministério da Saúde, Secretaria de Políticas de Saúde.

Brazil (2001). Portaria $n^{\circ}$ 723. Brasília: Ministério da Saúde, Diário Oficial, 14 de maio de 2001. (Brasilian Law)

Brazil (2004). Portaria GM/MS n 1258. Brasília, 28 de junho de 2004. (Brasilian Law)

Carvalho, S. R. (2004). As Contradições da Promoção à Saúde em Relação à Produção de Sujeitos e a Mudança Social (Contradictions of Health Promotion Related with the Subjects Production and Social Challenge). Ciência \& Saúde Coletiva, 9, 669-678. http://dx.doi.org/10.1590/S1413-81232004000300018

Drumond, E., Machado, C. J., \& França, E. (2007). Óbitos Neonatais Precoces: Análise de Causas Múltiplas de MortepeloMétodo Grade of Membership (Early Neonatal Mortality: Analysis of Multiple Cause of Death by Grade of Membership Method). Cadernos de Saúde Pública, 23, 157-166.

Duarte, C. M. (1992). Qualidade de Vida e Indicadores de Saúde: Aspectos da mortalidade Infantil no Estado do Rio de 
Janeiro e suas Regiões (Quality of Life and Health Indicators: Aspects of Infant Mortality in the State of Rio de Janeiro and Its Regions). Cadernos de Saúde Pública, 8, 414-417.

Formigli, V. L. A. et al. (1996). Avaliação da atenção à saúde através da investigação de óbitos infantis (Evaluation of Health Care through Research of Infant Deaths). Cadernos de Saúde Pública, 12, 33-412.

Gomes, M. A., \& Pereira, M. L. D. (2005). Família em Situação de Vulnerabilidade Social: Uma Questão de Políticas Públicas (Family in Social Vulnerability Situations: Issue of Public Policy). Ciência \& Saúde Coletiva, 10, 357-363. http://dx.doi.org/10.1590/S1413-81232005000200013

Goulart, L. M. H. de F. et al. (2003). Avaliação da Ação de Vigilância à Morbimortalidade Infantil na periferia de belo Horizonte, Minas Gerais (Evaluation of Child Morbidity Surveillance Action on Belo Horizonte Periphery, Minas Gerais). Revista Brasileira de saúde Materno-Infantil, 3, 291-301.

Goulart, L. M. H. de F., Somarriba, M. G., \& Xavier, C. C. (2005). A Perspectiva das Mães sobre o Óbito Infantil: Uma Investigação além dos números (Mother's Perspective on Child Death: Inquiry beyond the Numbers). Cadernos de Saúde Pública, 21, 715-723.

Mansano, N. H. et al. (2004). Comitês de Prevenção da Mortalidade Infantil no Paraná, Brasil: Implantação e Operacionalização (Prevention of Infant Mortality Committees in Paraná, Brazil: Implementation and Operationalization). Cadernos de Saúde Pública, 20, 329-332.

Menezes, A. M. B. et al. (1996). Mortalidade Infantil em duas Coortes de Base Populacional no Sul do Brasil: Tendências e Diferenciais (Infant Mortality in Two Population-Based Cohorts in Southern Brazil: Trends and Differentials). Cadernos de Saúde Pública, 12, 79-86.

Menezes, A. M. B. et al. (1998). Fatores de Risco para Mortalidade Perinatal em Pelotas, RS, 1993 (Risk Factors for Perinatal Mortality in Pelotas, Brazil, 1993). Revista de Saúde Pública, 32, 209-216. http://dx.doi.org/10.1590/S0034-89101998000300002

Mosquera, J. J. M., \& Stobäus, C. D. (1984). Educação para a Saúde: Desafios para Sociedades em Mudança (Health Education. Challenges for Changing Societies) (2nd ed.). Porto Alegre: DC. Luzzatto Editora.

Passebon, E., Bloch, K. V., Kale, P. L., \& Coeli, C. M.(2006). Associação entre Peso ao Nascer e Mortalidade Infantil no Município de Campos dos Goytacazes-RJ (Association between Birth Weight and Infant Mortality in the City of Goytacazes-RJ). Cadernos de Saúde Coletiva, 14, 283-296.

Rio Grande do Sul (2003a). Resolução $n^{\circ}$ 146/2003-CIB/RS. Diário Oficial do Estado do Rio Grande do Sul, Porto Alegre, 22 de outubro de 2003. (State Law)

Rio Grande do Sul (2003b). Resolução $n^{\circ}$ 147/2003—CIB/RS. Diário Oficial do Estado do Rio Grande do Sul, Porto Alegre, 12 de setembro de 2003. (State Law)

Rio Grande do Sul (2005). Estatísticas de Saúde: Mortalidade 2004. Núcleo de Informações em Saúde, Secretaria da Saúde, Statistics in Health, Mortality Statisticts 2004, Porto Alegre.

Silveira, D. S., dos Santos, I. S., \& da Costa, J. S. D. (2001). Atenção Pré-Natal na Rede Básica: Uma Avaliação da Estrutura e do Processo (Prenatal Care in the Basic Network: Assessment of the Structure and Process). Cadernos de Saúde Pública, 17, 131-139.

Stobäus, C. D., \& Mosquera, J. J. M. (2004). Criatividade (Criativiy). In J. C. Lane, N. A. Andreollo, \& M. Mantovani (Eds.), $O$ Processo de Ensino e Aprendizagem em Medicina (The Process of Teaching and Learning in Medicine) (2nd ed., pp. 155-156). São Paulo: Fundo editorial Byk. 
Scientific Research Publishing (SCIRP) is one of the largest Open Access journal publishers. It is currently publishing more than 200 open access, online, peer-reviewed journals covering a wide range of academic disciplines. SCIRP serves the worldwide academic communities and contributes to the progress and application of science with its publication.

Other selected journals from SCIRP are listed as below. Submit your manuscript to us via either submit@scirp.org or Online Submission Portal.
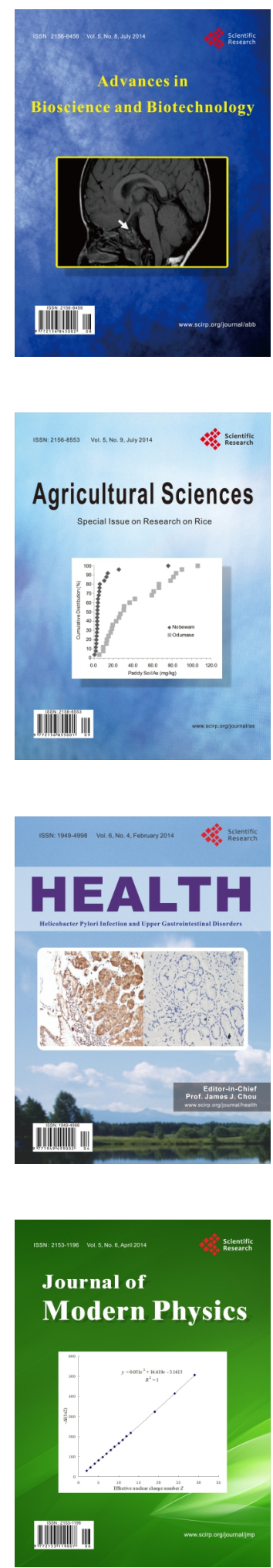
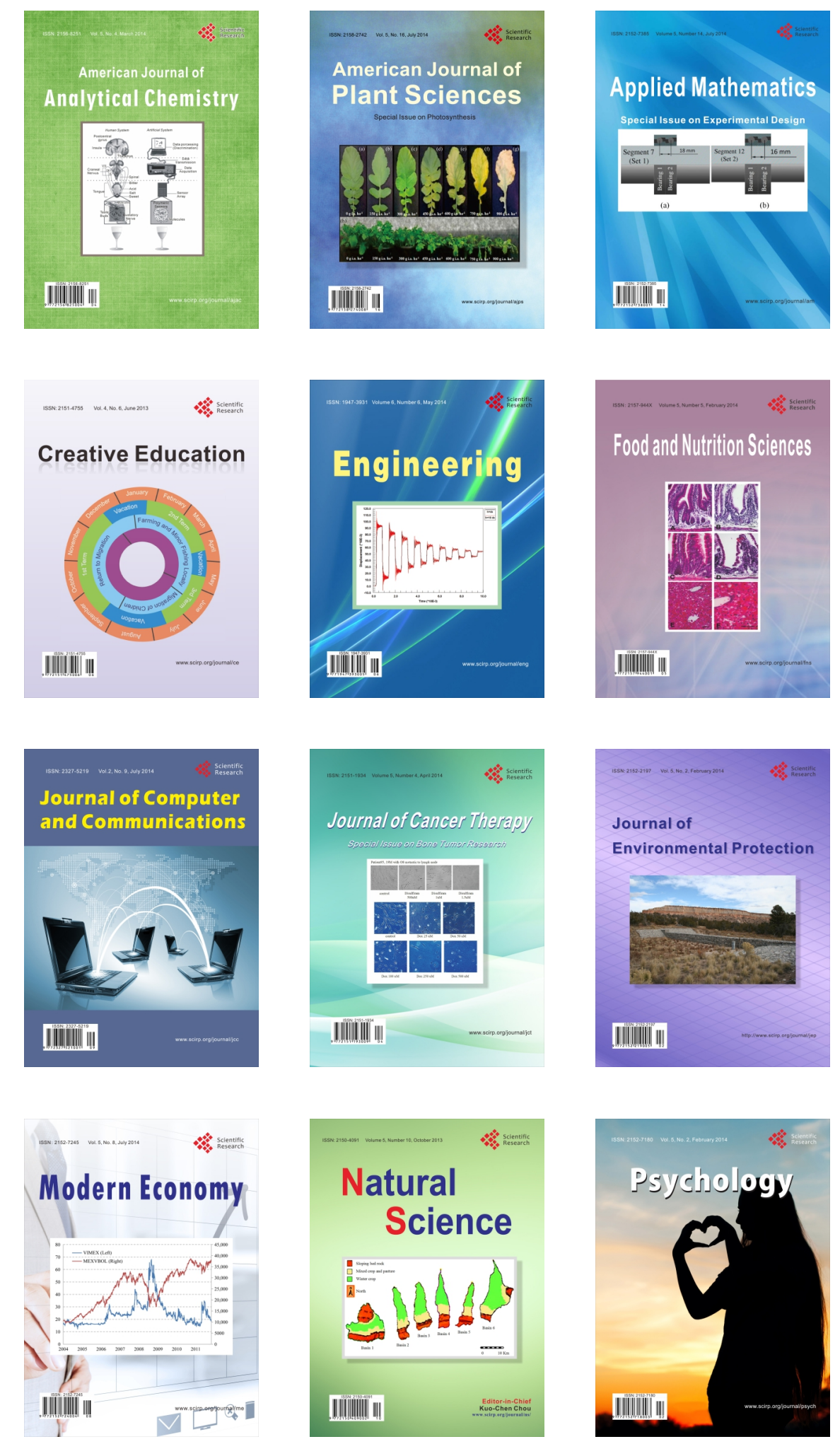